\title{
Financial Sustainability and Cost Recovery in Small Towns Water Systems in Eastern Region of Ghana
}

\author{
By Daniel Agyapong* \\ Michael Asiamah ${ }^{+}$ \\ Safuratu Muhammed Andani
}

\begin{abstract}
The sustainability of water facilities is one of the major challenges in the delivery of safe water to rural communities and small towns in Ghana. This study therefore aimed at assessing the financial sustainability of the small towns water systems in the Eastern Region based on the level of cost recovery. Secondary Data collected from various STWS were used. Variables of interest were analysed using descriptive statistics and a random effect regression, and a pooled logit regression. Interviews were also conducted. The study found more than 50\% of the STWS in Eastern Region are unable to raise their expected revenue. Again, the study revealed that most STWS are relatively efficient, having positive net-incomes after all expenditures, and improved remuneration and regular maintenance helps to improve revenue from STWS. Further, majority of the STWS are financially sustainable because the operation, maintenance costs and the capital maintenance costs are all recovered from tariffs. It was revealed that user financing of full implementation costs for STWS is an unrealistic goal and that cost recovery for on-going service delivery, recurrent operation, and maintenance may be a more achievable target. It is recommended that the WSMT managing the STWS should be equipped with financial management skills for effective management of the revenue generated from the STWS. They should undertake regular maintenance and repairs and improve staff remuneration to increase productivity, improve revenue generation, and enhance the financial sustainability of the STWS. The Municipal and District Assemblies should monitor the activities of the WSMT and provide technical support in terms of budgeting, financial reporting and auditing of their accounts to contribute to the financial sustainability of the STWS.
\end{abstract}

Keywords: Financial Sustainability, Cost Recovery, Water System, Logit Model

\section{Introduction}

The management of natural resources receives increasing attention all over the world. The unsustainable exploitation of natural resources endangers the existence and welfare of current and future generations. One of these resources is water, which has increasingly become a locus of concern in several countries. The efficient management of water resources is vital for its sustainable access

\footnotetext{
* Research Assistant, Department of Management Studies, University of Cape Coast, Ghana.

${ }^{\dagger}$ Department of Management Studies, University of Cape Coast, Ghana.

* Department of Management Studies, University of Cape Coast, Ghana.
} 
and use. However, despite the intensive efforts by many institutions at both national and international levels, access to safe drinking water and its sustainable management is still a formidable challenge in most communities around the world. WHO/UNICEF Joint Monitoring Programme for Water Supply and Sanitation (2012; 2014), indicates that nearly three-quarters of the world's poor, who live in rural areas in developing countries, do not have access to safe drinking water. Those who even have are not able to effectively manage it to ensure sustainability.

Every year, millions of the world's poorest people die from preventable diseases caused by inadequate Water supply, Sanitation and Hygiene (WASH) services. Diarrheal diseases are the most common water-related diseases and a major cause of deaths worldwide with an estimated 1.8 million people dying from diarrheal diseases each year, including 4,000 children under five years of age who die from diarrhoea every day (WHO, 2000). The inadequate supply of safe drinking water and improved sanitation is a serious public health concern in Ghana, contributing to $70 \%$ of diseases in the country (UNICEF, 2006). This is as a result of limited financial resources to provide, maintain and extend the water supply and sanitation infrastructure (UNICEF, 2006). Consequently, households without access to clean water are forced to use unhygienic sources and often pay more for it (Khedr, 2007).

Since the declaration of the International Drinking Water Supply and Sanitation Decade (1980-1990), governments of developing countries and development partners have stepped-up their efforts to ensure water for all. The Community Water and Sanitation Agency (CWSA) was established in 1998 to facilitate the provision of safe drinking water and related sanitation services to rural communities and small towns in Ghana. Over the years, the CWSA has facilitated the provision of Water and Sanitation facilities to rural communities and small towns under the National Community Water and Sanitation Programme (NCWSP) funded by Government and Development Partners. With these interventions, there has been significant acceleration in the delivery of water and sanitation services to rural communities and small towns in Ghana. The Water and Sanitation Monitoring Platform (WSMP) in Ghana recently reported an increase in the rural water coverage from $28 \%$ in 1992 to $63.41 \%$ by the end of 2012. Beyond the provision of water facilities however, lies the issue of effective management of the facilities to ensure sustainable service delivery.

In Ghana, several institutional arrangements have emerged over the years, all focusing on the efficient management of water supply to ensure sustainability. Comprehensive reforms of the Ghanaian water sector were initiated by the Bretton Woods Institutions in the 1990s. The Government of Ghana was obliged to restructure the sector by establishing regulatory bodies, opening the sector to private sector participation and separating responsibilities for urban water supply from rural water supply. Following this, the Ghana Water Company Limited (GWCL) was created to be solely in charge of urban water supply (UNESCO, 2005; Ministry of Water Resources, Works \& Housing, 2007; Asantewaa, 2013). The Community Water and Sanitation Division of the then Ghana Water and Sewerage Corporation was then transformed into the Community Water and 
Sanitation Agency, with the mandate for provision of safe water and related sanitation services to rural communities and small towns.

Cost recovery of water services is important in ensuring adequate financing for operations, maintenance, repairs and rehabilitation. A study conducted by Pilgrim (2002) revealed that the failure to recover the cost of water services from small town's water supply systems in Ghana may be due to low tariffs, poor management capacity of the Water and Sanitation Management Teams (WSMTs) and misuse of funds. Low tariffs for water services results in inadequate funds for operations which, then leads to declining levels of service. Consumers' willingness to pay for water services is dependent on the accessibility and quality of service. Thus, with the declining levels of service, consumers are unwilling to pay for the poor service and the reduction in revenue means there is no cash surplus to invest for rehabilitation or expansion.

This paper therefore sought to assess the financial sustainability of the small towns water systems in the Eastern Region based on the level of cost recovery. Specifically, this paper sought to achieve the following objectives: Determine the actual revenue from tariffs as against the expected revenue from the Small Town Water Systems (STWS) in the Eastern Region; Determine whether the revenue from tariffs is sufficient to cover operation and maintenance costs of the STWS; Assess the level of cost recovery and financial sustainability of STWS; and Assess the financial management capability of the WSMTs.

\section{Literature Review}

A survey of water charges in 122 developing countries by Over, Ellis, Huber and de Solon (1992) revealed that there was no cost recovery in $28 \%$ of the countries, and only part of the operation and maintenance costs were recovered in $30 \%$ of the countries.

In a study conducted by Nyarko, Oduro-Kwarteng, and Adama (2007) in five small towns in Ashanti Region indicated that, none of the water systems was recovering the full supply cost. The tariffs being charged were recovering 51$84 \%$ of the full supply cost of the water services. Thus, four of the communities were recovering only the operation and maintenance costs and one community was not even recovering the operation and maintenance costs in full. Moreover, the operation and maintenance costs of the water systems studied were found to be high; between $50-65 \%$ of the full supply cost of the water services. Furthermore, in another study by Nyarko, Oduro-Kwarteng, and Akonor (2003) in the Eastern and Volta regions, out of ten small town water systems they investigated only two were recovering the full cost of the water services. The rest were recovering only the operation and maintenance costs. 


\section{Methodology}

This section covers the source data used and the research design and approach. The second section looks at the analytical and econometric tools used in the analysis. The first subsection of the analytical and econometric tools used for the study describes the panel estimation technique for identifying the determinants of STWS revenue in the Eastern Region. The second subsection describes the pooled logit regression that was adopted for identifying the determinants of the sustainability of STWS in the Eastern Region of Ghana. The last subsection describes the method for the analysis of data.

\section{Description of Study Area}

The study area comprises twenty (20) communities in thirteen (13) municipal/ district assemblies in the Eastern Region of Ghana (Appendix A). The Eastern Region is the third most popular region after Ashanti Region and Greater Accra Region, lying between latitude $60^{\circ}$ and $70^{\circ}$ North and between longitude $10^{\circ} 30^{\prime}$ West and $0^{\circ} 30^{\prime}$ East. It is bounded on the East by the Volta Region, South by the Greater Accra and Central Regions, North-West by Ashanti Region and to the North by the Brong Ahafo Region. It covers a geographical area of 19,324 square kilometers, which constitutes about $13.28 \%$ of the total land area of Ghana.

Projected population of the Eastern Region as at December 2013 is 2,802,550. Of this 620,710 reside in the urban centres and the rural population is 2,181,840 (according to CWSA database DiMES). The population of the Eastern Region was 2,633,154 (2010 Census data). Of this $1,143,918$ resided in the urban centers and the rural population was $1,489,236$ with a growth rate of $2.1 \%$ (2010 census data).

Agriculture constitutes the major economic activity of the region, providing $67 \%$ of employment. About $72 \%$ of the region's population, which resides in rural areas, depends directly or indirectly on agriculture and related activities for their livelihood. Both cash and food crops are cultivated. The cash crops include cocoa, citrus, coffee, cola, pineapple, oil palm, rubber, cashew, citronella, sugar cane and banana. Livestock production and fishing also constitute an important part of agriculture in the region. The region can also boast of industrial activities such as mining, stone quarrying, palm oil processing, distilling, textiles, etc.

The small town water systems were constructed between 2004 and 2008. CWSA Eastern Region (CWSA-ER) facilitated the implementation of the projects, including water-related sanitation facilities and services, with funding from the Government of Ghana and Development Partners; the Danish International Development Agency (DANIDA), German Development Association (KfW/ GTZ) and the Department for International Development (DFID). The implementation of the projects was done by the MDAs, using foreign and local consultants and contractors as well as local artisans in the provision of works and services including training, with facilitation from CWSA. The beneficiary communities were actively involved in the implementation process and their 
capacities have been built through training and coaching to take up the operation and maintenance of the installed facilities.

\section{Data Source}

The main data set for this study was a panel data for twenty-three (23) Small Towns Water Systems in twenty-three (23) communities in the Eastern Region. It was mainly monthly secondary data sourced from the Community Water and Sanitation Agency in the Eastern Region on the monitoring of the systems from January 2011 to December 2013.

\section{Research Design and Research Approach}

In line with the objectives of the study, the study adopted the positivist philosophy within the framework of neoclassical economics. The positivist believe that reality is stable and can be observed and described from an impartial viewpoint without interfering with the phenomena being studied (Levin, 1988). Thus, positivist philosophy allows the researcher to study social processes in an objective manner as well as explain relationships between variables. More importantly, the positivist philosophy favours the use of quantitative approaches to research as used in this study. Positivist philosophy is suitable for the development of mathematical models to investigate the relationship between quantitative measurements. Based on the positivist philosophy, this study employed the quantitative method.

The quantitative approach is appropriate for this study because of the objective of the study which is to determine the sustainability of small town water systems in the Eastern Region. The quantitative approach enables the researcher to put the social world into a structure of causality and nullifies the role of human effect through the use of a quantitative instrument such as multivariate statistical analysis in analyzing data as used in this study. More specifically, since the objective of the study is explanatory in nature, the study adopted the explanatory research under the quantitative approach.

The research approach adopted in this study is to assess the recovery of operation and maintenance cost as indicated by Brikke' Bredero, Supply, and Network (2003) and any cash surplus for capital maintenance (replacement and rehabilitation of the facility). This is because it is generally accepted that user financing of full implementation costs (i.e. full cost recovery from tariffs) for improved rural water systems is an unrealistic goal (Harvey and Reed, 2004). Cost recovery for ongoing service delivery and recurrent operation and maintenance may be a more achievable target (Cardone and Fonseca, 2003). Franceys and Gerlach (2012) also suggest that if all investments are financed by grants, then revenue generated from tariffs should be sufficient to cover operation and maintenance costs. 


\section{Econometric Technique}

\section{Model Specification (Panel estimation)}

Since a major part of the study is to identify what determines revenue levels of STWS in the Eastern Region, the study estimated a regression model that seeks to identify the determinants of revenue from STWS in the Eastern region. The study used total revenue from sales of water as the main dependent variable (rev). Accordingly, we specify a model in which "REV" is our dependent variable to identify the determninants of revenue from STWS in the Eastern Region. The relevant models are shown below:

$$
\begin{aligned}
R E V_{i t}=\beta_{0}+ & \beta_{1} \ln M C_{i t}+\beta_{2} \ln H R S_{i t}+\beta_{3} \ln M P_{i t}+\beta_{4} \ln R E N_{i t}+\beta_{5} \ln M A_{i t} \\
& +u_{i t}(1)
\end{aligned}
$$

Where:

$\ln M C=\log$ of metres cube of water consumed

$\ln H R S=\log$ of hours of pumping

$\ln M P=\log$ of metres cube of water pumped

$\ln R E N=\log$ of expenditure on remuneration

$\ln M A=\log$ of expenditure on maintenance and repairs

$\beta_{0} . . \beta_{5}=$ Intercept and slope terms

$u_{i t} \quad=$ the error term

\section{Estimation Technique}

Unlike the normal pooled ordinary Least Squares (OLS) regression, Panel data regression techniques take into consideration the various biases and other disturbances that may come up in the regression analyses by controlling the unspecified differences among STWS that are not easily incorporated in practice. The study employs the panel data model below:

$$
\begin{aligned}
Y_{i t}=\alpha_{i}+\theta_{t} & +\beta^{\prime} X_{j i t} \\
& +\varepsilon_{i t}
\end{aligned}
$$

$\alpha$ denotes cross sectional heterogeneous effect which is time invariant, $\theta$ is the individual heterogeneity effect, $X_{j i t}$ represents a vector of explanatory variables, $i$ represents the $i^{\text {th }} \mathrm{STWS}_{j} j$ is the number of independent variables and $t$ is the year. $\varepsilon$ captures the unobserved time specific effect and is the idiosyncratic error term.

Since our analysis involves the use of panel data, using the ordinary least squares (OLS) method would result in ignoring the differences between different STWS and this would have made it impossible to determine the direction of error, giving rise to heterogeneity bias. The study therefore employed the fixed effects and random effects model in its estimation. However, the major problem is in 
selecting between the Fixed Effect (FE) and the Random Effect model (RE) models. The FE model allows for arbitrary dependence between the unobserved effect $\theta$, and the explanatory variables $X_{i t}$ (Wooldridge, 2010), hence they become fixed parameters to be estimated. Here we transform the dependent and independent variables and then apply OLS to the transformed data to obtain the within estimator. The FE model alters the estimating equation so as to eliminate the fixed effects (Baltagi, 2008).

Under a RE model the unobserved effects $\theta$ s, are assumed to be random and the estimation procedure used is the generalized least squares (GLS). The GLS uses cross-section weights for every observed STWS at time t, and the true variance elements, in order to produce a matrix-weighted average of the within and the between which is gotten by regressing the cross section averages across time estimators (Baltagi, 2008; Greene, 2008).

It is important to mention, however, that both the fixed and random effect models assume that the errors are independently and identically distributed (i.i.d). This suggests the absence of heteroskedasticity and auto-correlation. When this assumption is violated, these models will yield inefficient or invalid estimates. Rogers (1994) propose the estimation of RE or FE model employing the Rogers or clustered standard errors in the presence of non i.i.d. residuals. Relaxing the assumption of independently and identically distributed residuals, this estimator produces robust standard errors if the residuals are correlated within but uncorrelated between clusters which gives rise to heteroskedasticity and auto correlation consistent estimates.

Driscoll and Kraay (1998) maintained that even when the residuals from the FE and RE models are i.i.d, the existence of cross sectional correlation across clusters or cross sectional dependency, might render the estimates inefficient or invalid. In addition, estimates from the traditional Hausman specification tests are also invalid in the presence of spatial correlation. Driscoll and Kraay (1998) consequently proposed a model with residuals that are robust to very general form of cross sectional as well as temporal dependence.

\section{Logit Model}

According to Gujarati (2012), the commonly used models, when the dependent variable is dichotomous, are the binary logit and probit models. The probit and logit models are indistinguishable from each other except for their tails; with the logit model having a fatter tail. The choice between logit and probit models is largely one of convenience and convention, since the substantive results generated are indistinguishable (Long and Marquis, 2002). For the purpose of this study the logit model is preferred because it is computationally simpler. The probit model was not used because of the nature of the variables used in the study, since the probit model assumes cumulative normal distribution (NketiahAmponsah, 2009).

To determine the probability that the $i$ th STWS is sustainable, the functional form for the logit model can be expressed as follows; 
$P_{i j}=\frac{1}{1+e^{\left(x_{i t} \beta+\varepsilon_{i t}\right)}}$

Where $P_{i j}$ represents the probability of the ith STWS becoming sustainable or not, $x_{i t}$ is the vector of explanatory variables; $\beta$ is the parameter to be estimated and $\varepsilon_{i t}$ is the stochastic error term. The stochastic error term component captures errors in model specification including omission of relevant variables and errors in data measurement.

The logistic equation can be rearranged into a linear form by converting the probability into log odd or logit;

$\operatorname{logit}\left(P_{i j t}\right)=\ln \left\{\frac{P_{i j t}}{1-P_{i j t}}\right\}=x_{i t} \beta+\varepsilon_{i t}$

According to Nketiah-Amponsah (2009), logistic regression enables researchers to predict a discrete outcome from a group of variables that may be continuous, discrete, dichotomous or a combination of these. The predictor variable in logistic regression can take any form because it makes no assumption about the distribution of the independent variables (they do not have to be normally distributed, linearly related or of equal variance within each group).

However, to determine the probability that the ith STWS becomes sustainable, the empirical model for binary logit model to be estimated is specified as follows: it is to be noted that the selection of the explanatory variables were based on theory and literature reviewed (Nketiah-Amponsah (2009).

$P_{i j t}=\beta_{0}+\beta_{1 t} \ln M C_{i t}+\beta_{2 t} \ln S P_{i t}+\beta_{3 t} \ln P R_{i t}+\beta_{4 t} \ln R E N_{i t}+\beta_{5 t} \ln M A_{i t}$

$+\varepsilon_{i t}$

Where: $P_{i j t}=1$ if STWS contribute $20 \%$ or more of the monthly revenue from the STWS is paid into the replacement account $(\mathrm{j}=1)$ and equals zero otherwise $(\mathrm{j}$ $=0$ ). The interpretation of the estimated coefficients is complicated by the fact that the model is nonlinear in the explanatory variables. This means that the effect of independent variables on the probability of STWS becoming sustainable will depend on the value of that and other independent variables. For this reason, results are best interpreted through the analysis of marginal effects.

$\ln M C=\log$ of metres cube of water consumed

$\ln S P=\log$ of revenue from standpipes

$\ln P R=\log$ of revenue from private connection

$\ln R E N=\log$ of expenditure on remuneration

$\ln M A=\log$ of expenditure on maintenance and repairs 
The panel logit regression is more appropriate in the present study because we have a binary dependent variable in our panel dataset. Allison (2009) notes, that when we have panel data (the same subjects measured at two or more points in time) another alternative presents itself: we can use the subjects as their own controls. With binary dependent variables, this can be done via the use of conditional logit effects models. Hence the use of the logit model in the present study.

\section{Justification and Measurement of Variables}

\section{Metres Cube of Water Consumed}

This captures the daily consumption of water consumed by communities in which these STWS have been provided. When the consumption is high, STWS are expected to get more revenue and this would increase the probability of contributing at least 20 percent of the revenue into the replacement account. A positive relationship is therefore expected between metres cube of water consumed and sustainability of STWS.

\section{Revenue from Standpipes}

Revenue from standpipes is expected to contribute to the total revenue from STWS. This is because increase in the revenue from the standpipes feeds directly into the revenue stream of the STWS, which goes a long way to increase the amount of money available for contribution into the replacement account and hence a positive relationship is expected between sustainability and income from standpipes.

\section{Revenue from Private Connection}

Just like revenue from standpipes, revenue from private connection is expected to increase the total revenue from STWS and thus, have a positive relationship with sustainability of the STWS. This is especially so because of the higher consumption per capita from private connection and the higher revenue per metre cube of water consumed.

\section{Expenditure on Remuneration}

Expenditure on remuneration basically captures the salaries and other allowances that staff of STWS receive on monthly basis for work done. An increase in the salaries of staff of STWS is expected to increase the level of motivation among staff and as a result increase their level of productivity and this could go a long way to improve revenue generation in within a particular STWS and hence increase the probability of that STWS contributing at least 20 percent of the revenue into the replacement account. On the other hand, where 
increase in remuneration of staff members of a particular STWS is not matched with increased productivity, then such increases in remuneration can only result in decrease in revenue and thus, a decrease in the possibility of a particular STWS contributing at least 20 percent of its revenue into the replacement account. Hence, a positive or negative relationship is expected between expenditure on remuneration and sustainability of STWS.

\section{Expenditure on Maintenance and Repairs}

Regular maintenance of equipment used by STWS is expected to increase the efficiency of the equipment and as such improve productivity and revenue generation of STWS. However, where expenditure on maintenance is not effective then this positive effect wouldn't be realised. Hence, a positive or negative relationship is expected between sustainability and expenditure on maintenance and repairs.

\section{A Priori expected Signs}

To facilitate interpretation of the demand effects of empirical values of the coefficients of the variables, we discuss in this subsection their expected signs. The expected signs of the coefficients for the independent variables in equation (5) are presented in Table 1.

Table 1. A Priori Expectations of Estimated Coefficients

\begin{tabular}{|c|c|c|c|c|}
\hline \multicolumn{5}{|c|}{ A Priori Expectations } \\
\hline$\beta_{1}>0$ & $\beta_{2}>0$ & $\beta_{3}>0$ & $\beta_{4}>/<0$ & $\beta_{5}>/<0$ \\
\hline
\end{tabular}

Source: Author's construct, 2014

Method of Data Analysis

Secondary Data collected from various STWS were converted from its raw form into a panel data form using Microsoft Excel. It was then converted into STATA for a more advanced analysis of the variables. Variables of interest were analysed using descriptive statistics, and presented in frequency tables and graphs.

The determinants of revenue from STWS were analysed using a random effect regression. A pooled logit regression was then used to analyse the factors that affect the sustainability of STWS in the Eastern Region.

\section{Results and Discussion}

This section presents the empirical analysis of the issues related to the sustainability of STWS. 


\section{Descriptive Statistics}

The results from the descriptive statistics indicate that most of the communities in the Eastern Region would be able to cover their operating cost. This is because the average revenue they obtain from their activities GHC4,861.59 exceeds their operating cost of about GHC3,291.34. Clearly, most STWS in the Eastern Region are operating relatively on an efficient scale given the fact that they are able to meet their expenses with some level of surplus. This is supported by the positive average net income of GHC1855.85, with a maximum net income of GHC351196.40.

However, considering the minimum value of the net income (GHC-31106), it gives an indication that some STWS in the Eastern Region are not operating efficiently since the revenue they obtain from their activities is unable to meet their operating cost. This may have serious implications for the sustainability of these STWS in the region.

Table 2. Descriptive Statistics

\begin{tabular}{|c|c|c|c|c|c|c|}
\hline Variable & & Mean & Std. Dev. & Min. & Max. & Observation \\
\hline \multirow{3}{*}{$\begin{array}{l}\text { OPERATION } \\
\text { AND } \\
\text { MAINTENANCE } \\
\text { AND CAPITAL } \\
\text { COST }\end{array}$} & Overall & \multirow{3}{*}{3543.4} & 3994.0 & 104.91 & 47413 & $\mathrm{~N}=679$ \\
\hline & Between & & 3086.8 & 1024.6 & 14967.3 & $n=23$ \\
\hline & Within & & 2637.9 & -5740.7 & 35989.1 & T-bar $=27.52$ \\
\hline \multirow{3}{*}{ Revenue* } & Overall & \multirow{3}{*}{4861,5} & 18314.0 & 298.3 & 354394 & $\mathrm{~N}=686$ \\
\hline & Between & & 4048.6 & 1316.8 & 15253.7 & $\mathrm{n}=23$ \\
\hline & Within & & 17832.8 & -6720.74 & 345981 & T-bar $=29.82$ \\
\hline \multirow{3}{*}{ Revenue** } & Overall & \multirow{3}{*}{5146.6} & 8726.9 & 104.8 & 199865 & $\mathrm{~N}=658$ \\
\hline & Between & & 4083.7 & 1470.7 & 20652 & $\mathrm{n}=23$ \\
\hline & Within & & 7576.6 & -13844.9 & 184360. & T-bar $=28.61$ \\
\hline \multirow[t]{3}{*}{ Net Income } & Overall & \multirow{3}{*}{1855.8} & 17731.8 & -31106 & 351196.4 & $\mathrm{~N}=731$ \\
\hline & Between & & 2997.206 & -60.80055 & 10523.35 & $\mathrm{n}=23$ \\
\hline & Within & & 17461.23 & -32446.87 & 342528.9 & T-bar $=31.7826$ \\
\hline
\end{tabular}

Note $*$ is Actual Revenue and ** is Expected Revenue. Differences in sample sizes due to missing observations

Source: CWSA- ER Monitoring Forms 2011- 2013

\section{Actual Revenue and expected Revenue}

An analysis of the actual revenue obtained by STWS and expected revenue shows that the mean value of the expected revenue (GHC5146.6) marginally exceeds the mean value of the actual revenue (GHC4861.5) obtained from the STWS. The implication of this result is that, on the average, STWS are unable to achieve their revenue targets at the end of every month. Table 3 represents a cross tabulation of expected revenue and actual revenue obtained by STWS in the Eastern region. 
Table 3. Actual Revenue versus Expected Revenue

\begin{tabular}{|l|c|c|c|c|c|c|}
\hline $\begin{array}{l}\text { Expected } \\
\text { Revenue }\end{array}$ & \multicolumn{7}{|c|}{ Actual Revenue } \\
\hline & $0-1200$ & $\begin{array}{c}1201- \\
2400\end{array}$ & $\begin{array}{c}2401- \\
3600\end{array}$ & $\begin{array}{c}3601- \\
4800\end{array}$ & $\begin{array}{c}\text { Above } \\
4800\end{array}$ & Total \\
\hline $0-1200$ & 20.00 & 14.2 & 2.14 & 0.84 & 0.61 & 6.39 \\
\hline $1201-2400$ & 36.92 & 40.24 & 24.29 & 15.13 & 2.44 & 22.53 \\
\hline $2401-3600$ & 21.54 & 25.44 & 45.71 & 14.29 & 3.01 & 21.77 \\
\hline $3601-4800$ & 9.23 & 14.79 & 16.43 & 35.29 & 9.15 & 16.89 \\
\hline Abav 4800 & 12.31 & 5.33 & 11.43 & 34.45 & 84.76 & 32.42 \\
\hline Total & $\mathbf{1 0 0}$ & $\mathbf{1 0 0}$ & $\mathbf{1 0 0}$ & $\mathbf{1 0 0}$ & $\mathbf{1 0 0}$ & $\mathbf{1 0 0}$ \\
\hline
\end{tabular}

Pearson $\mathrm{Chi}^{2}(16)=419.0990 \mathrm{Pr}=0.000$

Note: Figures in the table are column percentage

The results indicate that just about $20 \%$ of STWS whose average monthly revenue amounted to about $\mathrm{GHC} 1,200$ had revenues that were equivalent to their expected revenues. On the other hand about $80 \%$ of those STWS obtained revenues below their expected revenue. The results however improve with STWS with revenue levels between $\mathrm{GHC} 1,201$ and $\mathrm{GHC} 2,400$ as about $40.24 \%$ obtained their expected revenue levels. $14.2 \%$ of STWS within this category actually exceeded their expected revenue, whereas a little over 45 percent were unable to meet their revenue targets. Whereas $45.71 \%$ of STWS with revenue levels between $\mathrm{GHC} 2,401$ and $\mathrm{GHC} 3,600$ obtained their expected revenue, about 26\% exceeded their expected revenue and just about $28 \%$ of STWS within this category were unable to meet their revenue target. The results also indicate that STWS with revenue levels between GHC3,601 and GHC4,800 included 35.29\% that obtained their expected revenue and a little over $30 \%$ that exceeded their expected revenue. On the other hand, $34.45 \%$ of STWS within this category obtained revenue that was below their expected revenue. For STWS with revenue levels aboveGHC4,800, about $85 \%$ obtained their expected revenue levels, and about $15 \%$ of them exceeded their expected revenue. The results however, indicate that on the average, less than $50 \%$ of STWS in the Eastern region are able to meet their expected revenue.

The most efficient STWS are the large systems with revenue above GHC4,800, with all of them obtaining their expected revenue and about $15 \%$ actually exceeding their expected revenue. This can be attributed to less unaccounted-for water, highly motivated staff for improved revenue collection and better services from large schemes hence willingness of consumers to pay. A higher degree of maintenance culture among STWS increases the efficiency of equipment used for production, reduces losses and thus increases the chances of obtaining expected revenue from STWS.

\section{Revenue and Operating Cost}

Considering that the average revenue of STWS in the Eastern region exceeds their average operating cost, the study categorised the revenue and operating cost 
into five different categories and conducts a chi-square test to determine whether there exist a relationship between revenue and operating cost. The results of the chi-square test are presented in Table 4.

Table 4. Revenue versus Operating Cost

\begin{tabular}{|l|c|c|c|c|c|c|}
\hline $\begin{array}{l}\text { Operating } \\
\text { Cost }\end{array}$ & \multicolumn{7}{|c|}{ Actual Revenue } \\
\hline & $0-1200$ & $\begin{array}{c}1201- \\
2400\end{array}$ & $\begin{array}{c}2401- \\
3600\end{array}$ & $\begin{array}{c}3601- \\
4800\end{array}$ & $\begin{array}{c}\text { Above } \\
4800\end{array}$ & Total \\
\hline $0-1200$ & 85.71 & 26.24 & 7.28 & 0.81 & 4.85 & 21.70 \\
\hline $1201-2400$ & 12.38 & 59.56 & 51.66 & 33.06 & 3.64 & 33.93 \\
\hline $2401-3600$ & 0.00 & 9.84 & 31.13 & 33.06 & 13.94 & 17.72 \\
\hline $3601-4800$ & 0.00 & 2.73 & 7.95 & 16.94 & 15.15 & 8.65 \\
\hline Abav 4800 & 1.90 & 1.64 & 1.99 & 16.13 & 62.40 & 17.99 \\
\hline Total & $\mathbf{1 0 0}$ & $\mathbf{1 0 0}$ & $\mathbf{1 0 0}$ & $\mathbf{1 0 0}$ & $\mathbf{1 0 0}$ & $\mathbf{1 0 0}$ \\
\hline
\end{tabular}

Pearson $\mathrm{Chi}^{2}(16)=707.0910 \mathrm{Pr}=0.000$

Note: Figures in the table are column percentage

Table 4 presents the actual revenue and cost incurred by STWS in the Eastern Region. The results from the table indicate that over 85 percent of STWS in the Eastern Region with revenue levels of about $\mathrm{GHC1} 1,200$ are able to cover their operating cost, whereas over 14 percent are unable to cover their operating cost. With regards to STWS with revenue levels between GHC1,201 and GHC2,400, about 26.23 percent of STWS within this category had their operating cost being less than the revenue obtained. Close to 60 percent were able to just cover their operating cost while the rest had operating costs that exceeded the revenue obtained. STWS with revenue levels within the category of GHC2,401 GHC3,600 had close to 60 percent obtaining revenue levels that exceeded their operating cost. $31.13 \%$ of these STWS had revenue levels that could just cover their operating cost. In all, the potential to cover operating cost by STWS in the Eastern Region increases with increases in revenue. On the average more than 60 percent of STWS in the eastern region are able to cover their operating cost. This is in contrast with the study by Over, Ellis, Huber and de Solon (1992) where only part of the operation and maintenance cost was recovered in 30\% of 122 developing countries studied.

For all STWS with revenue levels in the various categories, more than 80 percent are able to cover their operating cost with over $60 \%$ of STWS in some categories having a positive net income. This confirms the positive average net income of GHC1855.85 shown in Table 2.

It can also be seen from the results that as the level of revenue of STWS increases their operating cost decreases. The reason for this could be that as the revenue from the STWS increases, they putin place measures that improve their level of efficiency and hence reduce the cost of operation. This enhances the profitability of the STWS, which also ensures that they are able to sustain their activities over a long period of time. The chi-square test of independence confirms this assertion as the results obtained from the test reject the null hypothesis of no relationship between the revenue and operating cost. 


\section{Level of Cost Recovery from STWS}

Given the fact that not all STWS in the Eastern Region are able to cover their operating cost, the study went further to assess the extent to which the STWS are able to recover costs from the revenue obtained from tariffs. The STWS were divided into three categories, on the basis of their net-income and the results are presented in Table 5A and Table 5B.

Table 5A. Range of Net-Income of STWS

\begin{tabular}{|l|c|c|c|}
\hline Range of Net-income & Frequency & Percent & Cumulative Percent \\
\hline-31106 to -1670 & 51 & 6.98 & 7.11 \\
\hline-1632 to 0 & 149 & 20.38 & 27.36 \\
\hline 1 to 200 & 79 & 10.81 & 38.17 \\
\hline 206 to 900 & 175 & 23.94 & 62.11 \\
\hline Above 900 & 276 & 37.89 & 100 \\
\hline
\end{tabular}

Source:CWSA- ER Monitoring Forms 2011- 2013

Table 5B. Net-income of STWS

\begin{tabular}{|l|c|c|c|}
\hline Net-income & Frequency & Percent & Cumulative Percent \\
\hline Negative Net-income & 155 & 21.2 & 21.2 \\
\hline Balanced & 45 & 6.16 & 27.36 \\
\hline Positive Net-income & 531 & 72.64 & 100 \\
\hline Total & 731 & 100 & \\
\hline
\end{tabular}

Source: CWSA- ER Monitoring Forms 2011- 2013

The results from the frequency table indicate that majority of STWS in the Eastern Region are able to meet their operation and maintenance cost from their internally generated revenue (mostly tariffs). Over six percent of the STWS in the Eastern Region were just able to meet their monthly operation and maintenance costs. These STWS had their expenditure being equal to their revenue (balanced) and there was no cash surplus left for capital maintenance or any other expenditure. About 73 percent of the STWS are able to meet their monthly operation and maintenance with some cash surplus for future expenditure (positive net-income).Out of this figure (i.e. $73 \%$ ) a little over 10 percent had net-income levels of between $\mathrm{GHC1}$ and $\mathrm{GHC} 200$; about 24 percent had net-income of between $\mathrm{GHC} 200$ and $\mathrm{GHC} 900$ and the rest (about 38\%) retained substantial amount of money (above GHC900) as net-income. This implies that about 78 percent of the STWS in the Eastern Region are able to recover their operation and maintenance costs in full. This is consistent with other findings obtained by Nyarko, Oduro-Kwarteng, and Adama (2007) for STWS in the Ashanti Region and also in Eastern and Volta Regions (Nyarko et al., 2003).

\section{Determinants of Revenue from STWS}

Since revenue is an important element in the sustainable operation of STWS, the study went a step further to analyse which variables determine the 
level of revenue that STWS obtain from their operations. The random effect regression model was used to establish which variables are significant in determining the revenue from STWS. It is important to mention that, before the random effect estimation technique was chosen, the study employed the Hausman Test to select between the fixed effect and the random effect models. The results of the Hausman test are presented in Table 6.

Table 6. Hausman Test

\begin{tabular}{|l|c|c|c|c|}
\hline & Fixed effect & \multirow{2}{*}{ Random effect } & Difference & $\begin{array}{c}\text { Sqrt(diag(V_b- } \\
\text { V_B) }) \text { S.E }\end{array}$ \\
\hline InMC & 0.2118 & 0.19179 & 0.020009 & 0.016379 \\
\hline InHRS & 0.09034 & 0.056378 & 0.033963 & 0.020892 \\
\hline InMP & 0.144083 & 0.195697 & -0.05161 & 0.041542 \\
\hline InREN & 0.446562 & 0.486585 & -0.04002 & 0.028081 \\
\hline InMA & 0.076205 & 0.07846 & -0.00225 & 0.004726 \\
\hline
\end{tabular}

$\mathrm{b}=$ consistent under Ho and Ha; obtained from xtreg

$\mathrm{B}=$ inconsistent under $\mathrm{Ha}$, efficient under Ho; obtained from xtreg

Test: Ho: difference in coefficient not systematic

$\mathrm{Chi}^{2}(5)=(\mathrm{b}-\mathrm{B})^{\prime}\left[\left(\mathrm{V} \_\mathrm{b}-\mathrm{V} \_\mathrm{B}\right)^{\wedge}(-1)\right](\mathrm{b}-\mathrm{B})=8.18$

Prob>chi ${ }^{2}=0.1468$

Source: CWSA- ER Monitoring Forms 2011- 2013

The results from the Hausman test indicate that we fail to reject the null hypothesis that, the difference in coefficients is not systematic and as such we estimate a random effect model for the revenue of STWS. The results of the random effect estimation are presented in Table 7.

Table 7. Revenue from STWS

\begin{tabular}{|l|c|c|c|c|}
\hline Dependent variable (Rev) & Coefficient & Robust Std. Err & $\mathrm{z}$ & $\mathrm{P}>\mathrm{z}$ \\
\hline InMC & 0.192 & 0.051 & 3.750 & 0.000 \\
\hline InHRS & 0.056 & 0.040 & 1.400 & 0.161 \\
\hline InMP & 0.196 & 0.074 & 2.650 & 0.008 \\
\hline InREN & 0.487 & 0.058 & 8.440 & 0.000 \\
\hline InMA & 0.078 & 0.024 & 3.240 & 0.001 \\
\hline Const & 0.931 & 0.533 & 1.750 & 0.081 \\
\hline
\end{tabular}

Source: CWSA- ER Monitoring Forms 2011- 2013

The results in Table 7 indicate that all the variables of interest had significant impact on the level of revenue from STWS in the Eastern region except the hours of pumping. The results show that increase in any of those variables results in an increase in the revenue obtained from STWS. Specifically, a percentage increase in the consumption level, for example, increases revenue of STWS by 0.19 . The results further indicate that, higher quantity of water pumped, higher remuneration of workers and higher level of maintenance of equipment all result in increases in the revenue of the STWS by $0.20,0.49$ and 0.08 respectively. That is, an increase in the remuneration of workers results in an increase in productivity of these workers which increases the revenue of STWS. Similarly, a higher degree of maintenance culture among STWS increases the efficiency 
of equipment used for production, reduces losses and thus increases revenue of STWS.

\section{Sustainability of STWS in the Eastern Region}

In order to identify the level of sustainability of the STWS in the Eastern Region, the study went a step further to examine percentage of revenue that is deposited into the replacement account of the STWS. The results in Table 5 show that about 73 percent of the STWS have positive net-income ranging between a few Ghana Cedis and over GHC 900. The study determined the net-income deposited into the replacement account of the STWS and what percentage of the total revenue the net-income represented. According to CWSA guidelines, at least 20 percent of total revenue from STWS should be deposited in a replacement account towards future replacement and rehabilitation of the facility. Thus, the replacement account gives an indication of the level of preparedness to replace worn-out capital equipment by the STWS. The range of percentages of total revenue that is placed in the replacement account is presented in Figure 3.

Figure 1. Deposits into Replacement Account

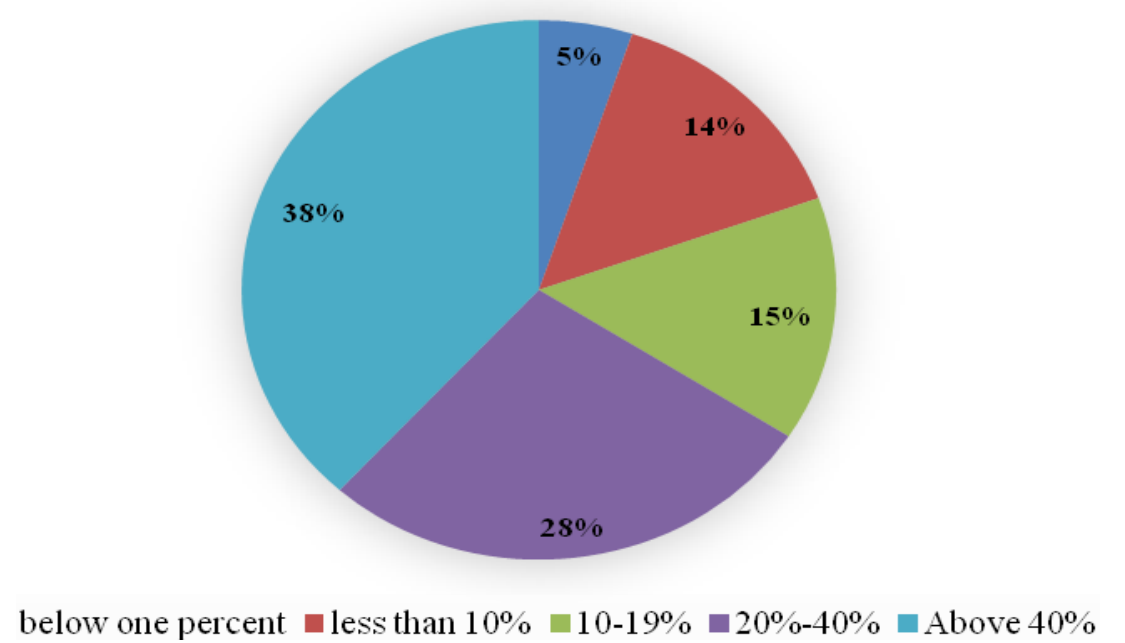

The Figure above represents the percentage of revenue that is deposited in the replacement account by the STWS. The results indicate that about 5 percent of STWS in the Eastern Region deposited less than one percent of their monthly revenue into their replacement account. In all about 34 percent of STWS in the Eastern Region deposited less than 20 percent of their monthly revenue into their replacement account. These STWS are not operating according to the CWSA guidelines and there is the possibility that they would not be able to cover the cost of replacing worn-out capital equipment when they are due for replacement. On the other hand about 66\% (in all) of STWS in the Eastern Region are more likely to meet the replacement cost of worn-out capital equipment when the time is due for replacement. This is because they are depositing more than 20 
percent of their monthly earnings into their replacement account with a high percentage of them (38\%) depositing more than 40\%, as indicated in Figure 3.

These results indicate that most STWS in the Eastern Region are able to meet their operating cost with cash surpluses to finance capital replacement. Seven of the STWS have undertaken major replacements, mostly pumps, in the past three years. Three of these STWS were able to finance the replacement from their operational account and the rest from their replacement account. One of the STWS is planning the extension of the water supply to new areas, to be financed from the replacement account. As suggested by McPhail and others (2012), since all investments are financed by grants, cash needs for the STWS are limited to operation and maintenance costs. The adequacy of revenues for meeting operation and maintenance costs and capital maintenance costs will therefore ensure the financial sustainability of these STWS in the Eastern Region.

As suggested by Harvey and Reed (2004) it may be unrealistic to expect revenue from tariffs to finance future system upgrade, rehabilitation and expansion costs due to lack of a transparent, secure and sustainable method of saving and investing money for future use and also the inability of users to pay for realistic tariffs to cover these costs. Even for those systems that are able to deposit $20 \%$ or more of their revenue into the replacement account, if the funds are not invested in appropriate accounts, against inflation, the accrued funds may not be sufficient for future system upgrade and rehabilitation. The CWSA Sector Guidelines (2010) provides for the communities to take up the cost of replacement and upgrading of the system from tariffs or other income, which could possibly come from the Municipal and District Assemblies.

\section{Determinants of Sustainability of STWS}

Most of the STWS in the Eastern Region have proven to be sustainable based on the percentage of deposits made into their respective replacement accounts. In this study, we categorised the STWS into Sustainable and Unsustainable. STWS that deposit more than 20 percent of their monthly revenue into their replacement account are categorised as Sustainable and given the value 1 and STWS that deposit less than 20 percent of their monthly revenue in their replacement account are categorised as Unsustainable and given the value zero. The study proceeded to estimate a panel logit regression on the determinants of sustainability of STWS in the Eastern Region. The results from the panel logit estimation are presented in Table 8 below. 
Table 8. Determinants of Sustainability of STWS

\begin{tabular}{|l|l|l|l|}
\hline Variable & Coefficient & Robust Std. Error & P-Value \\
\hline InMC & 1.0237 & 0.46592 & 0.028 \\
\hline InSP & 0.947176 & 0.222598 & 0.000 \\
\hline InPR & 0.353889 & 0.174038 & 0.042 \\
\hline InREN & 0.64444 & 0.281708 & 0.022 \\
\hline InMA & 0.29392 & 0.139792 & 0.036 \\
\hline Const & 5.34409 & 2.115823 & 0.012 \\
\hline Number of observations & & & 380 \\
\hline Number of groups & & & 20 \\
\hline Wald Chi ${ }^{2}(5)$ & & & 35.25 \\
\hline Prob> chi & & & 0.0000 \\
\hline Log likelihood & & & -217.136 \\
\hline Souce: CWSA-ER & & &
\end{tabular}

Source: CWSA- ER Monitoring Forms 2011- 2013

In all, a panel of 380 observations from 23 STWS in the Eastern region was used for the estimation and the Wald test statistic of the estimated model is significant at one (1) percent level. This suggests that the explanatory variables taken together influence or determine the sustainability of STWS in the Eastern Region. The log of metre cube of water consumed, the log of the revenue from standpipes, log of revenue from private connections, the log of expenditure on remuneration, and the log of expenditure on maintenance and repairs are all significant in predicting whether the STWS in the Eastern region are sustainable or not. This is indicated in Table 9.

Table 9. Marginal Effect of Determinants of Sustainability of STWS

\begin{tabular}{|l|l|l|}
\hline Variable & Marginal effect & P-Value \\
\hline InMC & 0.21717 & 0.024 \\
\hline InSP & 0.20094 & 0.000 \\
\hline InPR & 0.075076 & 0.041 \\
\hline InREN & 0.13672 & 0.023 \\
\hline InMA & 0.06235 & 0.038 \\
\hline
\end{tabular}

Source: CWSA- ER Monitoring Forms 2011- 2013

Results from Tables $8 \& 9$ show that the metre cube of water consumed is significant in determining the probability of STWS being sustainable. It is significant at 5\% level and has a positive correlation with the probability of STWS being sustainable. The positive coefficient of metre cube of water consumed implies that the probability of STWS being sustainable increases with increasing metre cube of water consumed. Thus, the marginal effect of 0.217 indicates that when there is a percentage increase in metre cube of water consumed, the probability of a particular STWS being sustainable increases by 22 percent.

Similarly, revenue from standpipes is also significant in determining the probability of STWS being sustainable. It is significant at $1 \%$ level and has a positive correlation with the probability of STWS being sustainable. The positive coefficient of revenue from standpipes implies that the probability of 
STWS being sustainable increases with increasing revenue from standpipes. Thus, the marginal effect of 0.2009 indicates that when there is a percentage increase in the revenue from standpipes, the probability of a particular STWS being sustainable increases by 20 percent. A similar result is obtained for revenue from private connections and the results indicate that a percentage increase in the level of revenue from private connections increases the probability of a particular STWS being sustainable by 7.5 percent.

Expenditure on remuneration and salaries and expenditure on maintenance and repairs both have positive correlation with the probability of STWS being sustainable. They were both significant at 5 percent level. The positive coefficients of expenditure on remuneration and salaries and expenditure on maintenance and repairs imply that the probability of STWS being sustainable increases with increasing expenditure on remuneration and salaries and expenditure on maintenance and repairs. Thus, the marginal effect of 0.14 and 0.06 for expenditure on remuneration and salaries and expenditure on maintenance and repair respectively indicates that when there is a percentage increase in expenditure on remuneration and salaries and expenditure on maintenance and repairs, the probability of a particular STWS being sustainable increases by 14 and 6 percent respectively.

The implication of the results is that high level of remuneration boost the morale of staff and they increase their productivity in response to increased remuneration. This improves the revenue generation of the STWS and hence increases the probability of the STWS being sustainable. Similarly, regular maintenance of equipment both capital and non-capital equipment helps improve productivity and efficiency of STWS which enhances the revenue generation and as such increases the probability of STWS being sustainable. The effect of the increase in revenue generation from the STWS is that the STWS are able to deposit the required minimum of 20 percent of the total monthly revenue into their replacement account, thereby increasing the probability of the systems being sustainable.

\section{Conclusion and Policy Recommendations}

The main objective of this paper was to assess the financial sustainability of the small towns water systems in the Eastern Region based on the level of cost recovery. The results obtained in this study clearly indicated that this objective was achieved. Based on the results obtained the following conclusions were reached; More than $50 \%$ of the STWS in Eastern Region are unable to raise their expected revenue given the fact that average revenue raised is less than expected revenue from their activities. Though more than $50 \%$ of the STWS are unable to raise their expected revenues, most of them are able to cover their operating costs. Most STWS in the Eastern region are relatively efficient, having positive net-incomes after all expenditures. Improved remuneration and regular maintenance helps to improve revenue from STWS. Increases in the revenue of STWS help improve productivity and efficiency of 
STWS in the Eastern Region. Majority of the STWS in the Eastern Region are financially sustainable because the operation and maintenance costs and the capital maintenance costs are all recovered from tariffs (CWSA, 2010). Majority of the WSMTs for the STWS in the Eastern Region are operating in a financially sustainable manner. The paper therefore recommends that; There is the need for STWS in the Eastern region to increase their revenue generation to help close the gap between expected revenue and actual revenue. STWS should also consider increasing their expenditure on maintenance in order to be able to undertake regular minor maintenance and repairs. This will go a long way to improve revenue and enhance sustainability of the STWS. Measures should be put in place by STWS in the Eastern Region to increase remuneration and improve staff motivation since well-motivated staff members increase their productivity and enhance revenue generation. The WSMTs managing the STWS should be equipped with financial management skills for effective management of the revenue obtained from their activities. For example the funds in the replacement accounts could be transferred to interest-bearing accounts until the funds are needed. Municipal and District Assemblies should support the STWS when the funds in their replacement accounts are not sufficient to upgrade the system or replace a major component in future.

\section{References}

Allison PD (2009) Fixed effects regression models (Vol. 160). SAGE publications.

Asantewaa P, (2013) Assessing the Status of Water Point Sources Case Study: Ejisu Juaben Municipality (Doctoral dissertation).

Baltagi B (2008) Econometric analysis of panel data, Vol. 1. John Wiley \& Sons.

Cardone R, and Fonseca C (2003) Financing and Cost Recovery. Switzerland: International Water and Sanitation Centre.

Brikké F, Bredero M, Supply W, and Network M (2003) Linking technology choice with operation and maintenance in the context of community water supply and sanitation: A reference document for planners and project staff.

Community Water and Sanitation Agency (CWSA) (1998) Small Towns Water and Sanitation Policy. CWSA, Ministry of Works and Housing, Government of Ghana.

Community Water and Sanitation Agency (CWSA) (2010) Small Towns Operation and Maintenance Guidelines. CWSA, Ministry of Water Resources, Works and Housing, Government of Ghana.

Community Water and Sanitation Agency (CWSA) (2012) CWSA Corporate Brochure.

Community Water and Sanitation Agency (CWSA) (2013) Framework for Assessing and Monitoring Rural and Small Towns Water Supply Services in Ghana.

Driscoll JC, and Kraay AC (1998) Consistent covariance matrix estimation with spatially dependent panel data. Review of economics and statistics 80: 549--560.

Franceys R, and Gerlach E (eds.) (2012) Regulating water and sanitation for the poor: Economic regulation for public and private partnerships. Routledge.

Greene WH (2008) Econometric Analysis. India: Pearson Education.

Gujarati DN (2012) Basic Econometrics. Tata McGraw-Hill Education.

Harvey PA, and Reed RA (2004) Rural Water Supply in Africa: Building Blocks for Hand pump Sustainability. WEDC, Loughborough University, UK. 
Khedr AAHM (2007) Socio-Economic Assessment of Water Supply in Rural Egypt (ElGharbia Governorate, Saft Torab Case) (Vol. 94). Oldenbourg Industrieverlag.

Nketiah-Amponsah E (2009) Demand for health insurance among women in Ghana: Cross sectional evidence. International Research. Journal of Finance and Economics 33: 14502887.

Nyarko KB, Oduro-Kwarteng S, and Adama I (2007) Cost recovery of communitymanaged piped water systems in Ashanti region, Ghana. Water and Environment Journal, 21(2), pp.92-99.

Nyarko KB, Oduro-Kwarteng S, and Akonor AO (2003) Implications of User Fee on Long Term Sustainability of Small Town Water Systems: A Case of Eastern and Volta Regions in Ghana.

Over M, Ellis RP, Huber JH, and Solon O (1992) The consequences of adult ill-health. The health of adults in the developing world, pp.161-207.

Pilgrim N (2002) Performance Indicators for Assessing Small Towns Water Supply Systems in Ghana. Ghana: CWSA.

Rogers W (1994) Regression standard errors in clustered samples. Stata Technical Bulletin 3.

United Nations Educational Scientific and Cultural Organisation (UNESCO) (2005) Water Resources Systems Planning and Management-An introduction to Methods, Models and Applications. The Netherlands.

United Nations Industrial Children's Education Fund (UNICEF) (2012) WHO Joint Monitoring Programme for Water Supply and Sanitation. Progress on drinking water and sanitation.

Wooldridge J M (2010) Econometric analysis of cross section and panel data. MIT press.

World Health Organization (2013) UNICEF Joint Monitoring Programme for Water Supply and Sanitation (2014). Progress on drinking water and sanitation, 2014 update.

WHO (2000) Joint Monitoring Programme for Water Supply and Sanitation, Coverage Estimates for Ghana.

United Nations Industrial Children's Education Fund (UNICEF) (2006) Progress for children: A report card on water and sanitation (No. 5). 
